\title{
EVOLUTION OF MOULD ARTHROPLASTY OF THE HIP JOINT
}

\author{
M. N. Smith-Petersen, Boston, Massachusetts, L....A.
}

Moynihan Lecture delivered in the Lniversity of Leeds, May 1947

Mr Dean and Members of the Faculty of Medicine: I am deeply appreciative of the honour of addressing you to-day as the fourth Moynihan Lecturer. I am particularly happy because this invitation implies recognition of the specialty of orthopaedic surgery. I am very grateful that you have chosen me as a representative of my specialty to give this lecture.

Arthroplasty is an operative procedure undertaken for the purpose of creating a joint. such a joint, if it is going to stand up under the wear and tear of function, must be mechanically as nearly perfect as possible. Until recent years this procedure as applied to the hip joint has met with limited success. There were three main reasons:

1. Surgical approaches were traumatic and inadequate; surgical shock commonly occurred even before the joint was exposed (Fig. 1).

2 . The joint created was defective because of lack of the proper instruments (Fig. 1).

3. The underlying principle, of interposing a perishable barrier between imperfectly. shaped joint surfaces, was not sound (Fig. 2).

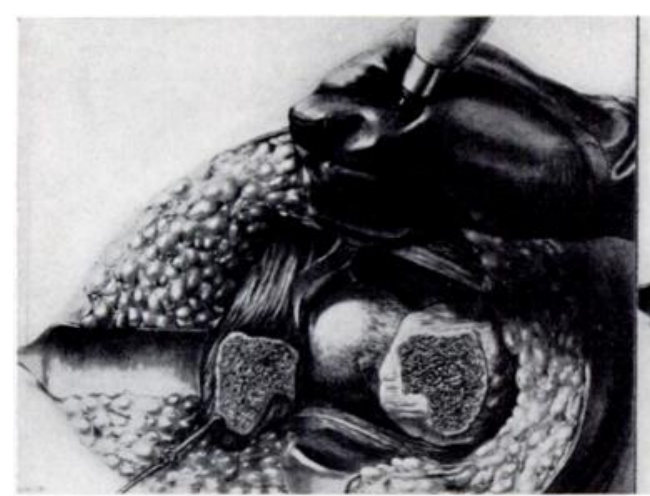

Fig. 1

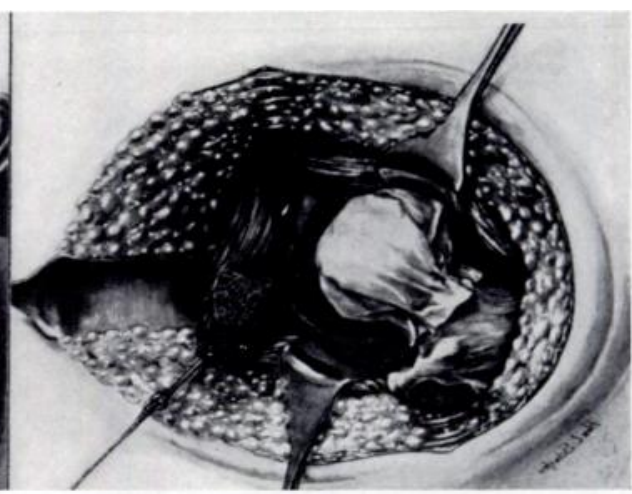

IIIG. 2

Dr William S. Baer was one of the outstanding orthopaedic surgeons of his time. He contributed much to the advancement of arthroplasty of the hip. The above illustrations are copied from lantern slides in his collection, made available through the kindness of D)r George E. Bennett.

Fig. 1 clearly demonstrates inadequate exposure of the acetabulum, making it impossible to reconstruct this side of the joint. It is interesting to note the carpenter's gouge with wooden handle. Fig. 2 shows the imperfectly shaped femoral head covered by a perishable harrier.

\section{DEVELOPMENT OF THE SURGICAL APPROACH TO THE HIP FOR ARTHROPLASTY}

The teachings of Dr Harvey Cushing-respect for structures and structural planeswere directly responsible for a new approach to the hip joint. After finishing my surgical internship at the Peter Bent Brigham, I started orthopaedic internship at the Massachusetts General Hospital in January 1916. In the spring of that year I assisted in an open reduction of a congenital dislocation of the hip. The hip was exposed through a Kocher incision; it was bloody; it was brutal. The patient survived by a very narrow margin. Being used to the technique of Dr Cushing I was shocked and I said to my senior, Dr Roy Abbott, "There must be some other way of exposing the hip." "Why don't you figure one out?" was his answer. That night, frontal bone flaps, approach to the pituitary, temporal decompression, exposure of the cerebellum, kept passing through my mind. In all of them, when the periosteum was reached it was cleanly incised, its edges were carefully elevated, and it was reflected intact, always as a continuous structure and never in shreds. 


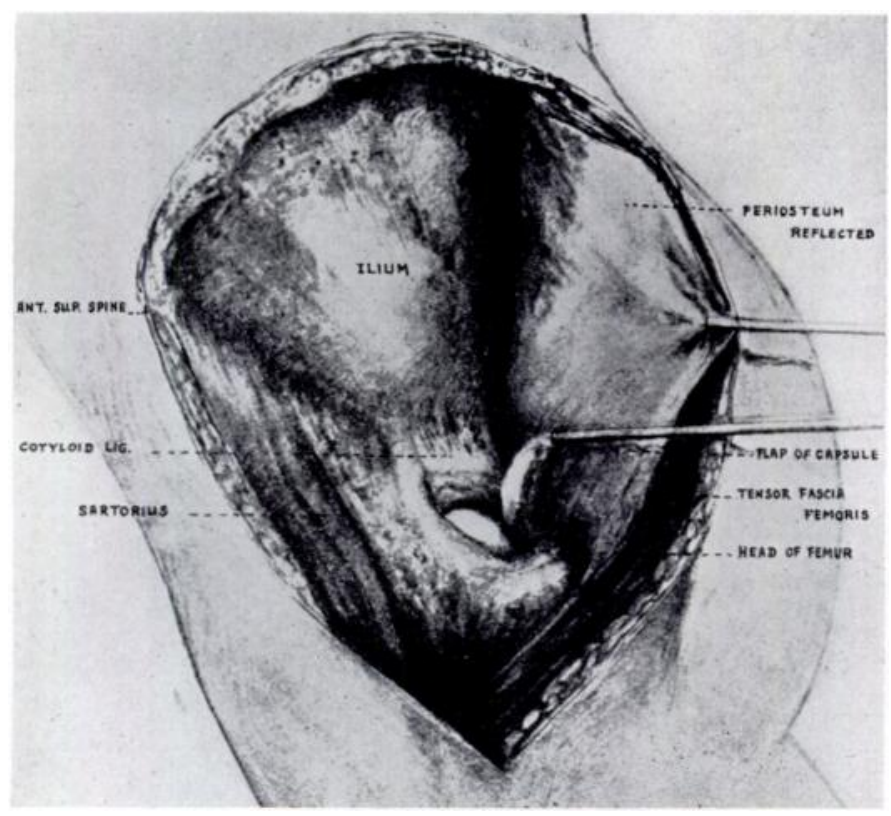

Fig. 3

Supra-articular subperiosteal approach to the hip as published in 1917-a poor, misleading illustration drawn from the anatomical specimen. Reflection of the periosteum was never carried out as extensively as shown. Even this approach gave inadequate exposure of the acetabulum.

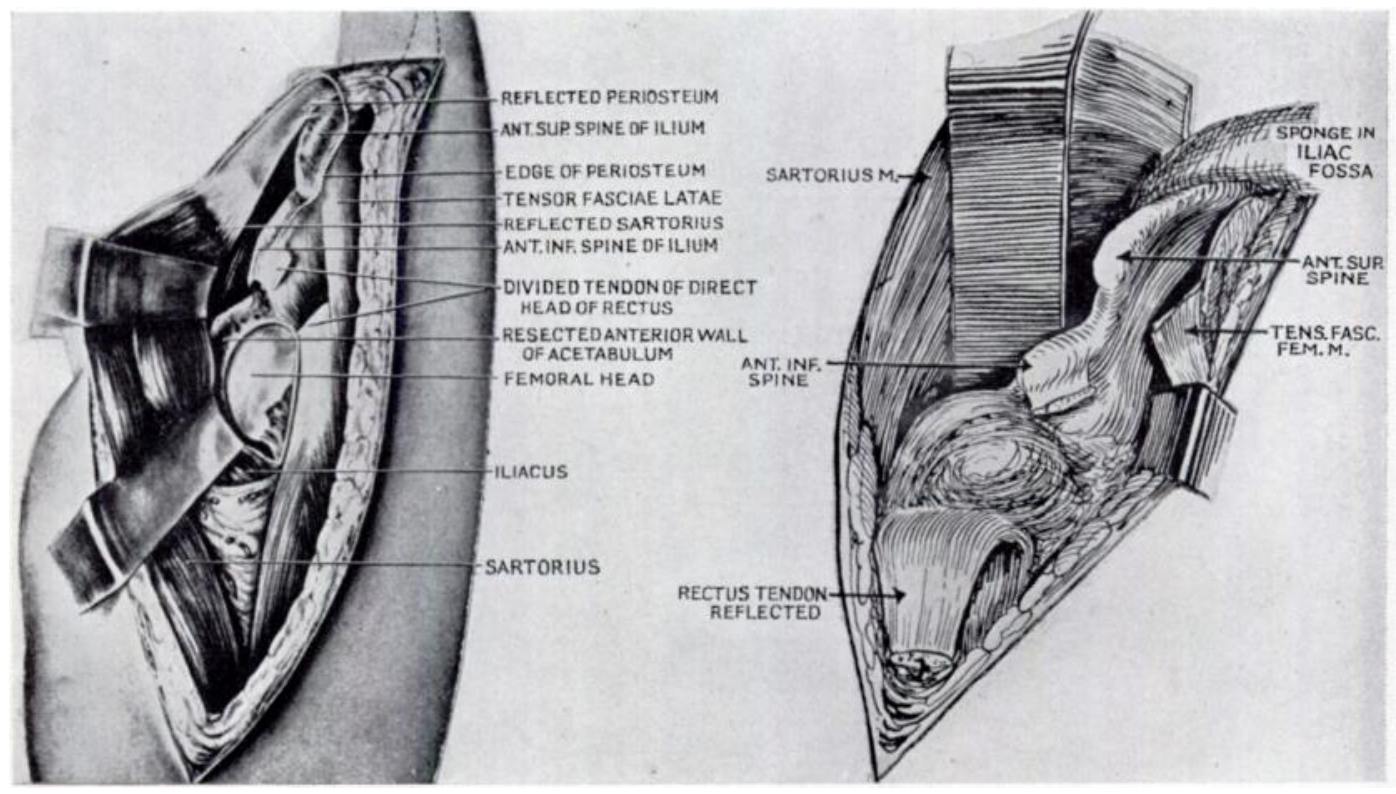

ligi. 4

Exposure of the hip for acetabuloplasty as published in 1935 . A mistake was made in saving a stump of the tendon of the rectus muscle and the anterior inferior iliac spine. By this approach the acetabulum was made accessible for reconstruction.
I. IG. 5

Exposure of the hip for mould arthroplasty as published in 1939. Nistake still being made of saving stump of rectus tendon and the anterior inferior spine. This resulted in calcification and spur formation requiring revision of the primary operation in several cases. 
The cerebellum exposure, by reflection of muscle flaps with their periosteal attachments, was probably the one that gave me the idea of combining the anterior hip approach with the periosteal reflection of muscles from the lateral aspect of the ilium.

The next day I went to the Medical School and asked my old friend, Tom Bonney, for a hip. He gave me a nice lean one: I can still see it (Fig. 3). It did not take long to demonstrate to my own satisfaction that the approach had merit, but would older and experienced surgeons feel the same way about it? I brought the specimen back to hospital and carefully hid it in the plaster-room under Ward 1. At the first opportunity I told the visiting surgeon that I thought I had a new way of exposing the hip joint. He laughed heartily and said "I like the enthusiasm of youth; if there were a better way of getting

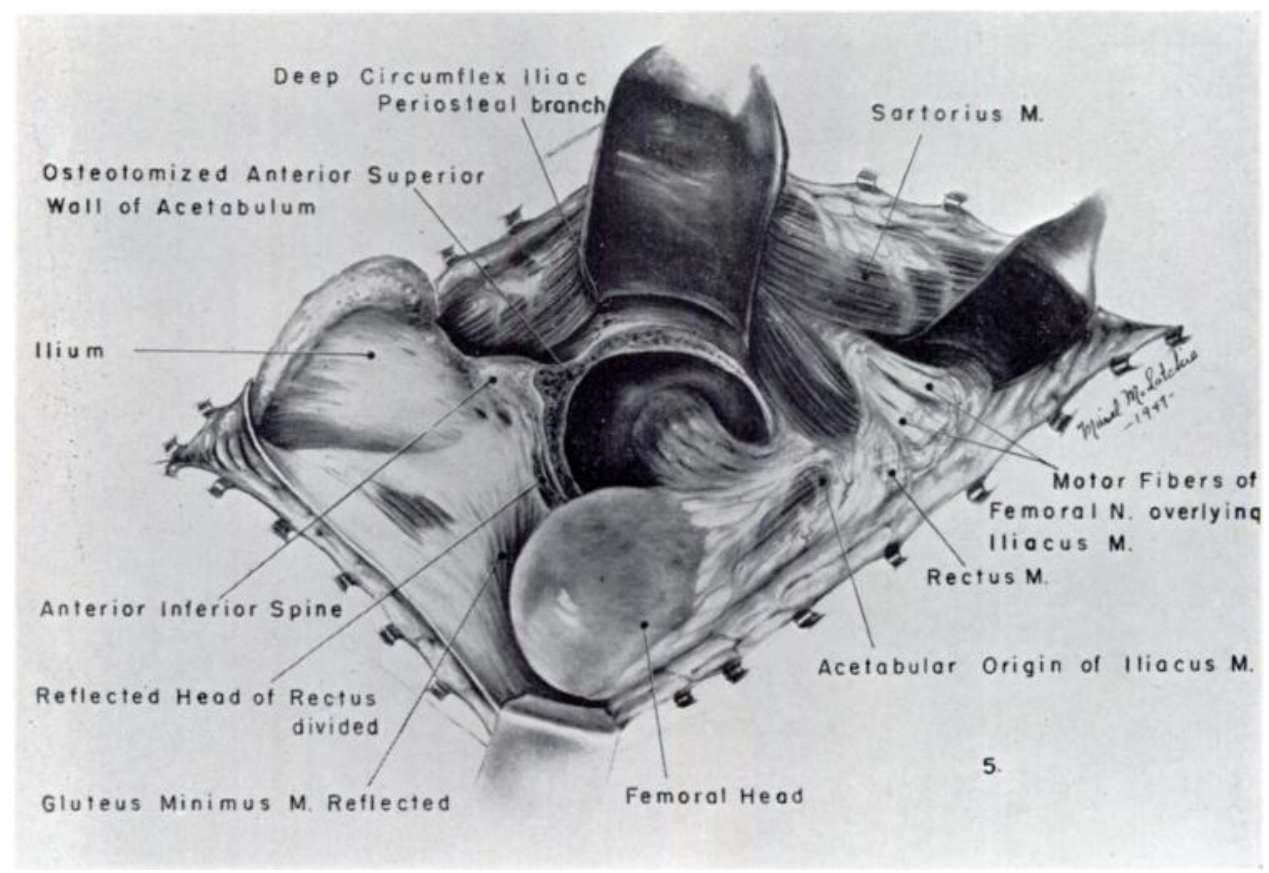

Fici. 6

Fiposure of the hip for mould arthroplasty as it is now done. It differs from the exposure of 1939 in two wass: 1. The direct head of the rectus muscle is divided at its attachment to the anterior inferior iliac spine and reflected laterally without being dissected out of its sheath: 2 . The inferior half of the anterior inferior iliac spine is sacrificed.

l)rawings of operative procedures are often misleading and make the surgeon feel " that 's easy."

This drawing shows the femoral head markedly displaced and gives the impression that the posterior rim of the acetabulum is within the field of vision. This is seldom possible.

The periosteum is represented as an unbroken, shinv sheet. It is possible to elevate the periosteum in this manner in young patients, but in older patients the periosteum becomes thin and friable and it is impossible to lift it off the ilium as a continuous structure. Care should always be exercised in elevating the periosteum; it should never be scraped off the ilium.

The motor fibres of the femoral nerve are a little out of proportion to the surrounding structures.

These fibres should always be exposed, at least partly; otherwise they are easily injured.

into the hip joint, don't you think that generations of surgeons who have gone before you would have discovered it a long time ago?" This was not exactly encouraging, so I did not invite him to see the specimen.

It was several days before the Chief of the Service, Dr Elliot G. Brackett, paid a visit to Mard 1. At the end of Rounds, I asked him if he would be interested in seeing a specimen which I thought demonstrated a new approach to the hip. "Why, certainly Doctor, of course I am " was his response. His reaction to the specimen itself was even more favourable: " You know 1)octor, I think that approach has possibilities. Would you allow me to take the specimen with me? I am going to the American Orthopaedic Association Meeting tonight and I would like to demonstrate it." Returning from the meeting he reported a very VOL. 30 B, No. 1, FEBRUARY 1948 
favourable reaction on the part of the older surgeons. In less than a year after this demınstration I had a nice letter from Dr Fred Albee telling me that he had used the approach on many occasions and that from then on he would use no other.

This supra-articular, subperiosteal approach to the hip improved the exposure of the head and neck of the femur, but the other side of the joint-the acetabulum-remained inaccessible. It was not until 1935 that this came within reach. " Acetabuloplasty "-excision of the anterior superior wall of the acetabulum-solved this problem (Fig. 4). This operative procedure was developed in an attempt to relieve a patient with bilateral, intrapelvic protrusion of the acetabula. The attempt was successful and for a number of years this operation was used quite commonly. Because of the increasing success of complete mould arthroplasty, it is now seldom used. We do owe it credit for showing us the way to expose the anterior acetabulum by subperiosteal reflection of the sartorius and iliacus muscles from the ilium. We owe it credit for proving that the anterior acetabulum can be excised without joint instability resulting. We owe it credit for starting our thoughts in the right direction. The making of a joint demands reconstruction of both sides of the joint so that the surfaces will be congruous and work smoothly in relation to one another (Fig. 5). The present exposure of the hip is extensive, but it is no more than adequate; and it is unaccompanied by shock because it respects structures and follows structural planes (Fig. 6).

\section{DEVELOPMENT OF INSTRUMENTS}

A carpenter has a work-bench with its vice. He can adjust his stock to any position necessary for good workmanship. He has good tools-so good that many surgeons advocate their use in bone surgery. A surgeon has no work-bench and no vice in which he can adjust his stock. His instruments, therefore, must be designed to overcome this difficulty;
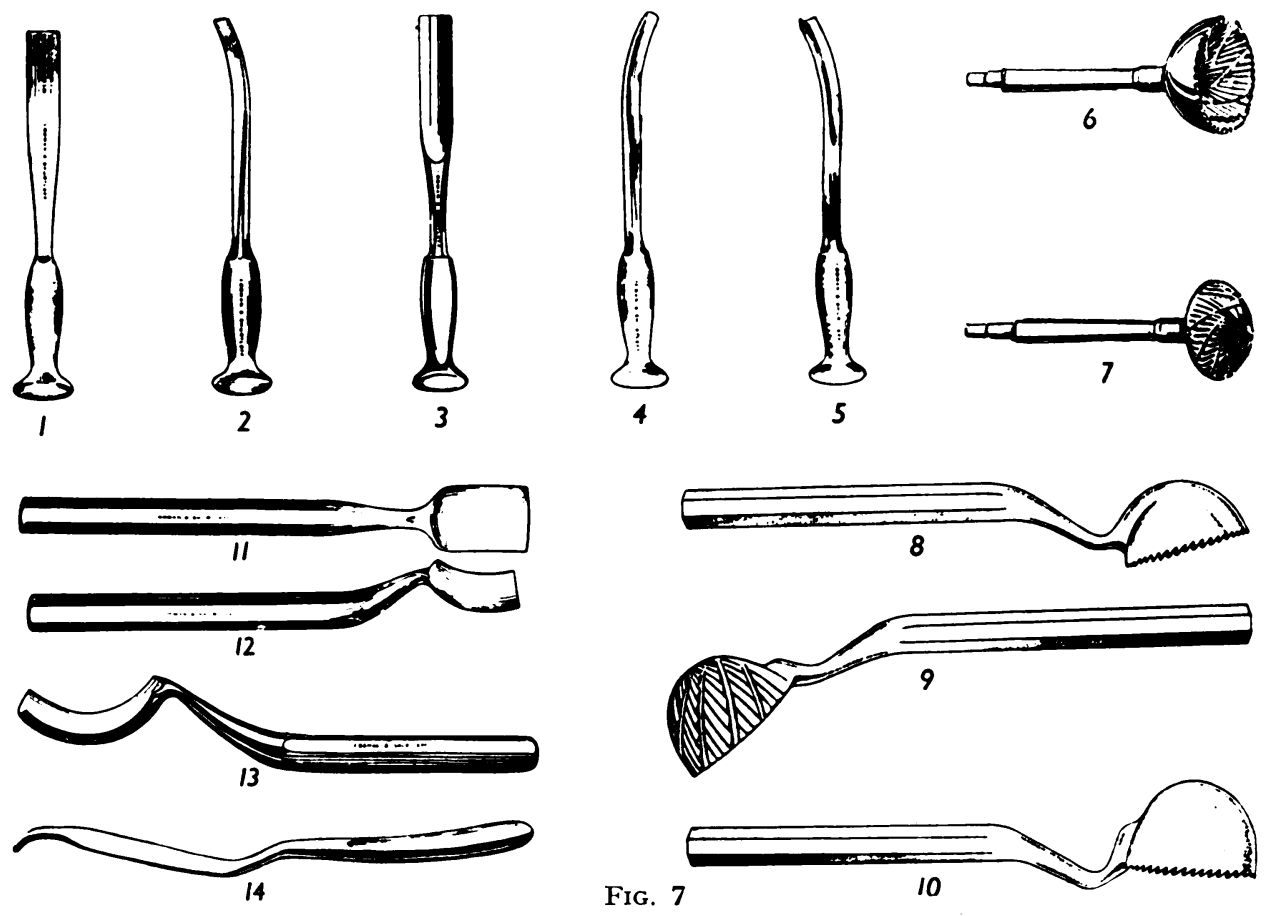

FIG.

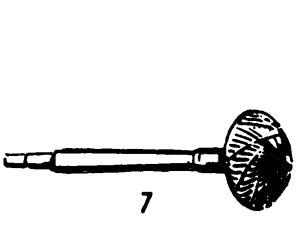

1: Thin straight osteotome; four widths, 2. Thin curved osteotome; four widths. 3: Thin straight gouges; four widths. 4: Thin curved gouges; four widths with corresponding curves. 5: Reversed gouge; three widths with corresponding curves; useful in undercutting acetabular margins. 6, 7: Female and male reamers for initial shaping of the femoral head and acetabulum. 8, 9, 10: Eccentric female and male reamers for final shaping of femoral head and acetabulum. making these surfaces congruous. 11, 12: Hip gouges first used in 1925; they have the same curves as the joint surfaces of a normal femoral head. 13: Large gouge first used in 1944; same curves as the smaller hip gouges; particularly useful in excising the posterior margin of the acetabulum. 
they must reach places out of sight, cut away bone around the corner, and polish surfaces inaccessible to the rasp or file.

Gouges of various sizes with curves corresponding to the surfaces of a normal hip joint have been in use since 192:5 (Fig. 7). It is thrilling to watch them disappear from sight. knowing that if given the proper start they cannot go wrong.

Irregular, uneven surfaces do not make a joint fit to function. Special reamers, with the same curves as the gouges, have been designed for the purpose of making the new joint surfaces smowth and congruous. These again work in the dark, but they work safely and efficiently:

Iany other instruments have been designed from time to time, each aiming to overcome some technical difficulty, so that we can now say we no longer miss the carpenter's bench or his vice.

\section{PRINCIPLE OF MOULD ARTHROPLASTY}

The hip joint is a fulcrum exposed to the leverage of the strongest muscles in the body. and to the trauma of weight-bearing. A joint exposed to such stresses with every step must indeed be mechanically perfect, almost without friction, if it is going to have lasting function. With this in mind it seems justifiable to say that any type of arthroplasty depending upon defective joint surfaces and the interposition of a perishable barrier is bound to have limited success. Fascia lata and similar perishable goods have been used for this purpose for almost forty years, and many satisfactory results have been reported by surgeons who have had extensive experience with this method. The percentage of failures, however, has been relatively high, and the functional results in terms of range of movement have been disappointing (Figs. 10-11).

In 19:23 a piece of glass was removed from a patient's back; it had heen there for a vear. It was surrounded by a minimal amourit of fibrous tissue, lined by a glistening

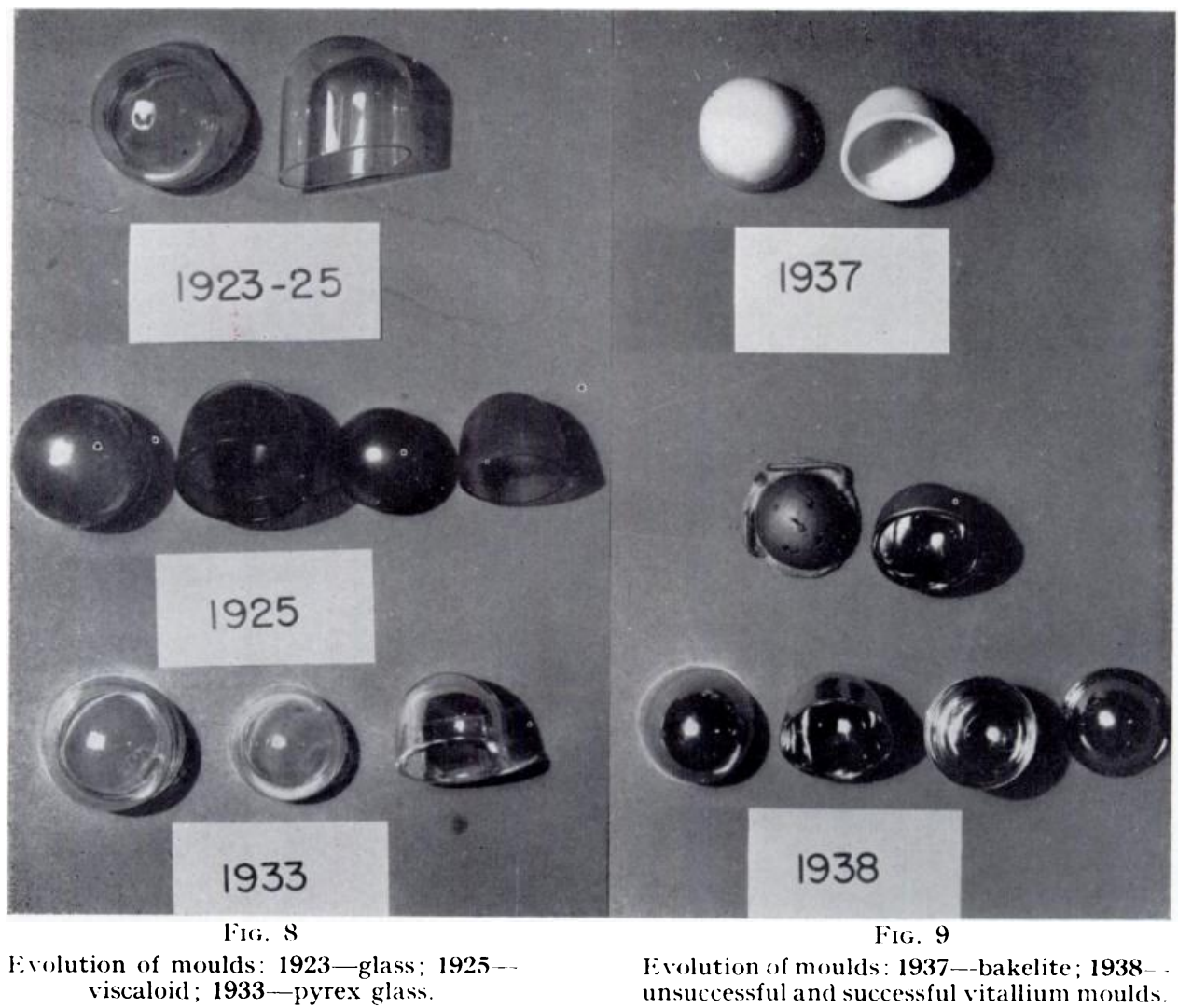

VOL. $30 \mathrm{~B}$, No. 1 , FEBRCARY 1948 
synovial sac, containing a few drops of clear vellow fluid. This benign reaction to an inert foreign body gave rise to the thought that here was a process of repair which might be applied to arthroplasty. This first thought gradually developed and the idea of the "mould" was conceived. A mould of some inert material, interposed between the newly shaped surfaces of the head of the femur and the acetabulum, would guide nature's repair so that defects would be eliminated. Upon completion of repair the mould would be removed, leaving smooth, congruous surfaces mechanically suited for function (Figs. 8-9).

Glass naturally suggested itself as the inert material from which moulds could be constructed. Macalister Bicknell of Cambridge, Massachusctts, who made the first X-ray tube for Dr Walter Dodd, made the first crude moulds. Looking back upon these moulds now, I am amazed that I had the courage to use them. The fact that I did illustrates the value of a professional family. such as we have at the Massachusetts General Hospital. I needed someone to lean on. Who should it be? Ir C. Allen Porter was my

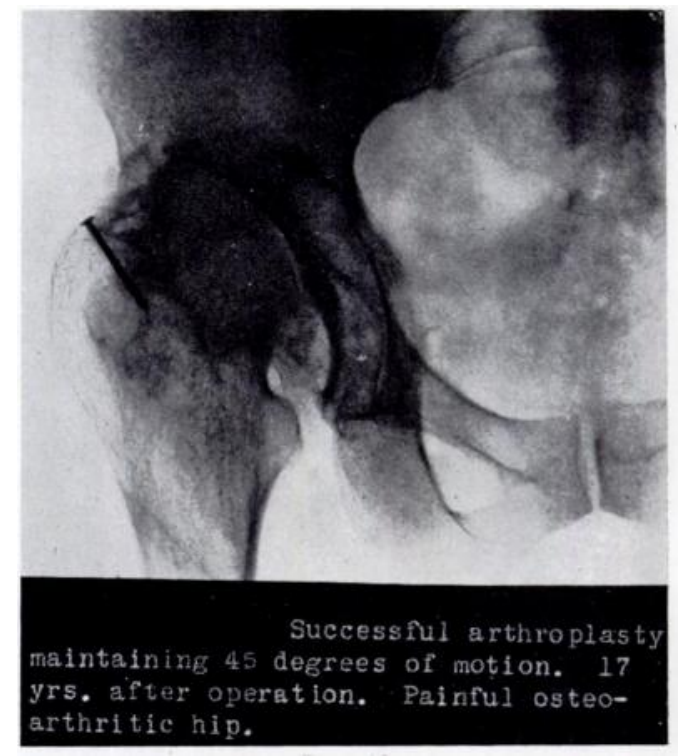

FIG. 10

The arthroplasty in this case resulted in a mechanically imperfect joint. Such a joint does not improve with use; it deteriorates.

choice. Time and again he sat down with me--answered questions, analysed doubt:, and encouraged me to carry on.

The day after constructing the first glase mould arthroplasty I received a call to see Dr George Holmes in the old X-ray Department, the former accident room. "What are

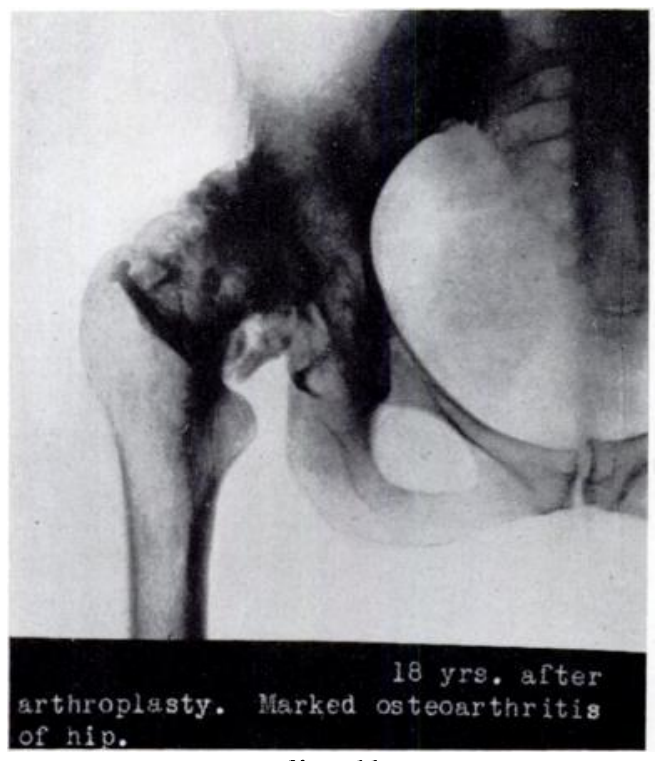

Fig. 11

This film demonstrates an acetabulum which has not been reconstructed. Inadequate exposure and lack of proper instruments made this impossible. confining the surgical procedure to the femoral head does not create a joint with lasting function. you up to now?" He was looking at two $\mathrm{X}$-ray plates (not films) taken of the same patient. "Here we have bony" ankylusis of the hip and here, twenty-four hours later, we have what appears to be a joint lined by cartilage." I explained. George laughed and shook his head. "What will you be up to next?" This was in 192:3.

Some of the glass moulds broke after having been in place a matter of months. This was a disheartening experience but it had one encouraging aspect. When the pieces were removed, the acetabulum and head of the femur were found to be covered by a firm, glistening lining. We had somie evidence, then, that the principle of guiding nature's repair by means of a mould was sound. The original glass moulds were abandoned and the search went on for some other material, inert and strong enough to stand up under weight-bearing.

Viscaloid, a form of celluloid, was tried first experimentally and later clinically, but 
it produced too much foreign body reaction and had to be given up. Eight years went by without success. In 1933 we went back to the use of glass, this time "pyrex." The moulds were considerably heavier and were tested under the polariscope for evidence of strain under compression. Theoretically they were strong enough but practically they were not. Some of them broke. Since we could not trust them, they were used only in selected cases and not on an extensive scale. The majority of these patients did well. When the moulds were removed after fifteen to tiventy-five months the joint surfaces were smooth, glistening, firm, and congruous. Histological examination of specimens removed showed fibro-cartilage around the periphery of the articular surfaces, and hyaline cartilage in the central portion (Fig. 12). Since the central portion is the part of the joint most exposed to the intermittent pressure and friction of weight-bearing, it seems reasonable to conclude that metaplasia from fibro-cartilage to hyaline cartilage takes place in response to these physiological physical stresses. The principle involved in mould arthroplasty may be represented diagrammatically as follows:
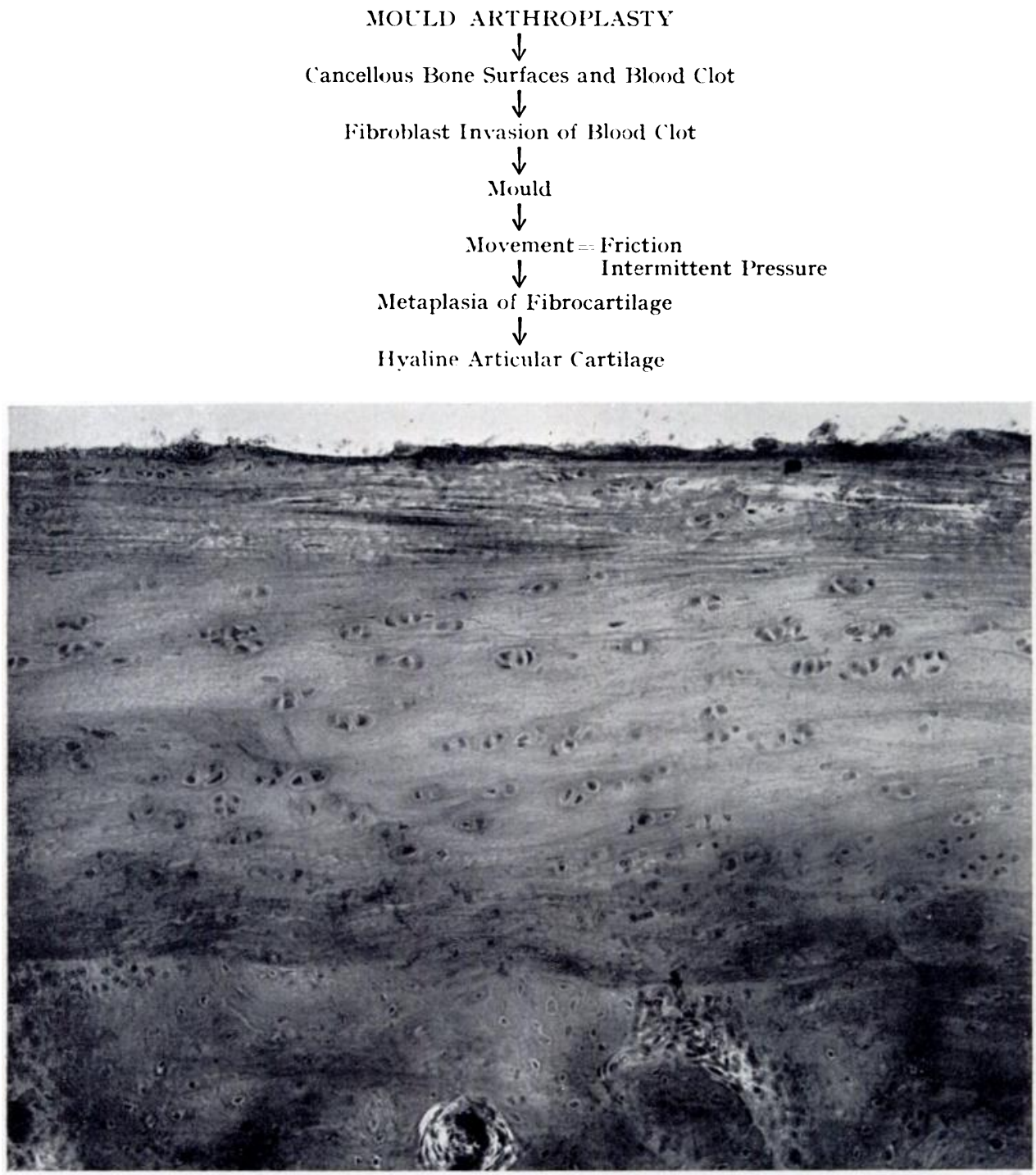

Fig. 12

Micro-photograph of specimen removed at operation twenty-five months after glass-mould arthroplasty. Hyaline cartilage. Homogeneous matrix and typical cartilage cells. Arrangement of cells less regular than in normal cartilage.

vol. $30 \mathrm{~B}$, No. 1, FEBREARY 1948 


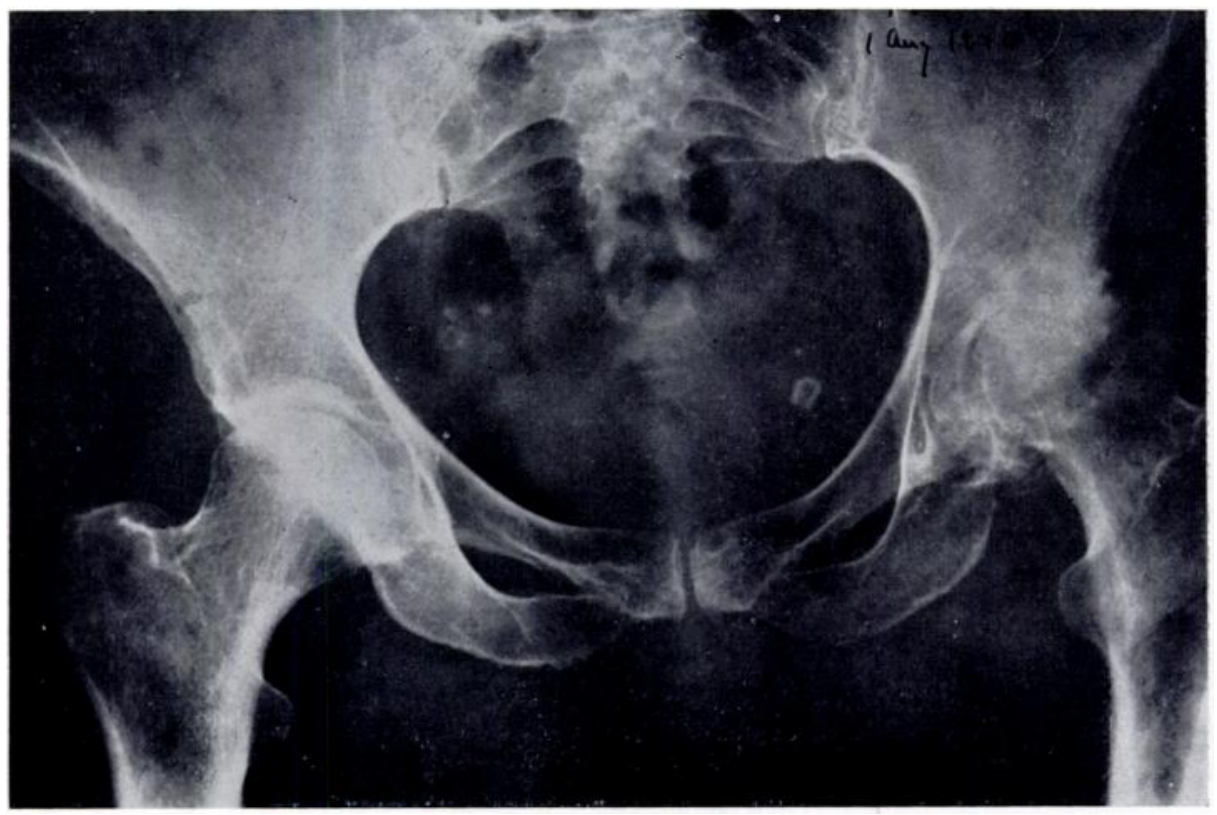

FIG. 13

H. F. Typical case of malum coxae senilis in a patient seventy-four years old. Marked flexion, adduction, and external rotation deformity. Dependent upon medicine for sleep. Operation justified by patient's excellent physical condition.

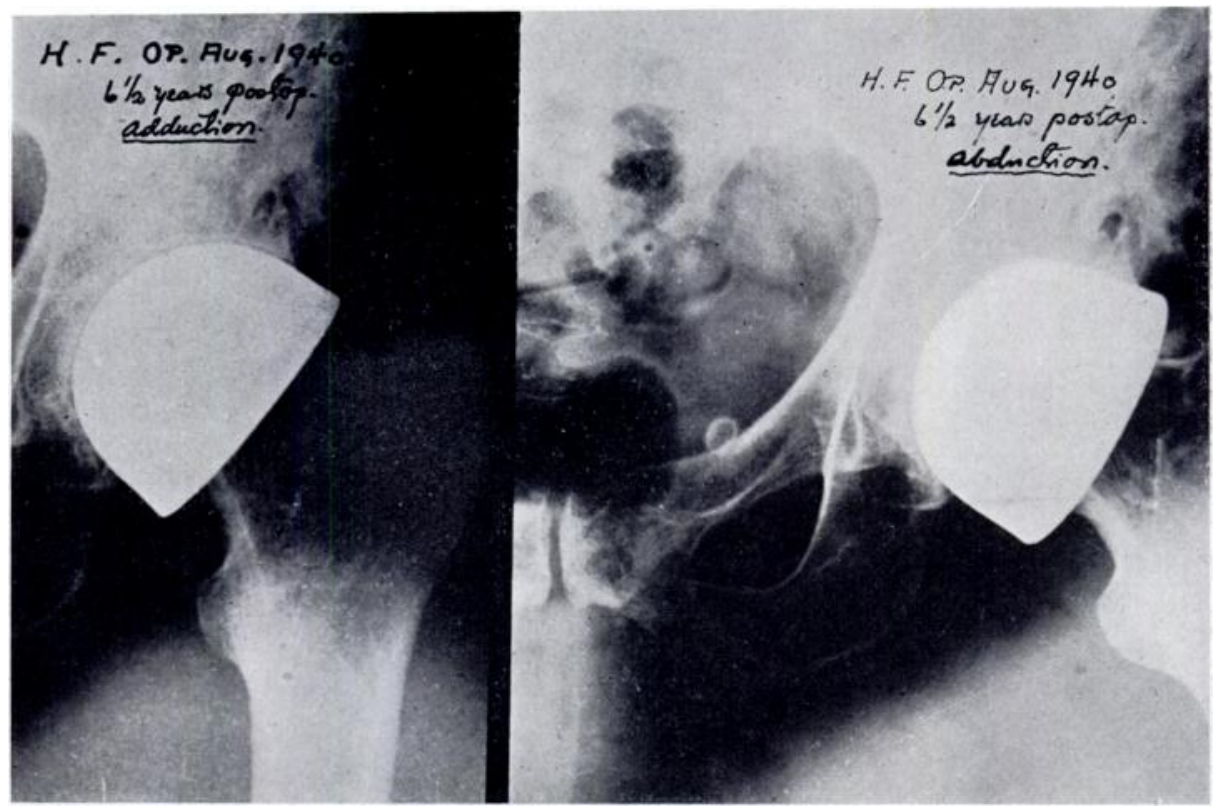

FIG. 14

H. F. Same patient as in Fig. 13, six and a half years after operation. Patient now eighty years old. No symptoms arising from the hip which has been operated upon. Walks without a limp. Range of movement better than on the opposite side. No flexion deformity. Novements-flexion to 120 degrees, internal rotation 15 degrees, abduction 25 degrees.

Criticisms: Marked proliferative bone changes on the lateral surface of the ilium. The surgeon may not have been sufficiently careful in elevating the periosteum. It is also possible that the post-operative dressing may not have been sufficiently snug to prevent oozing and resulting formation of a subperiosteal haematoma. The acetabulum was not made as deep as we now make it. In view of the excellent functional result, we must point out that the depth of the acetabulum varies with the local conditions encountered. This case'was selected because it is very instructive and the result of operation is extremely satisfactory. 


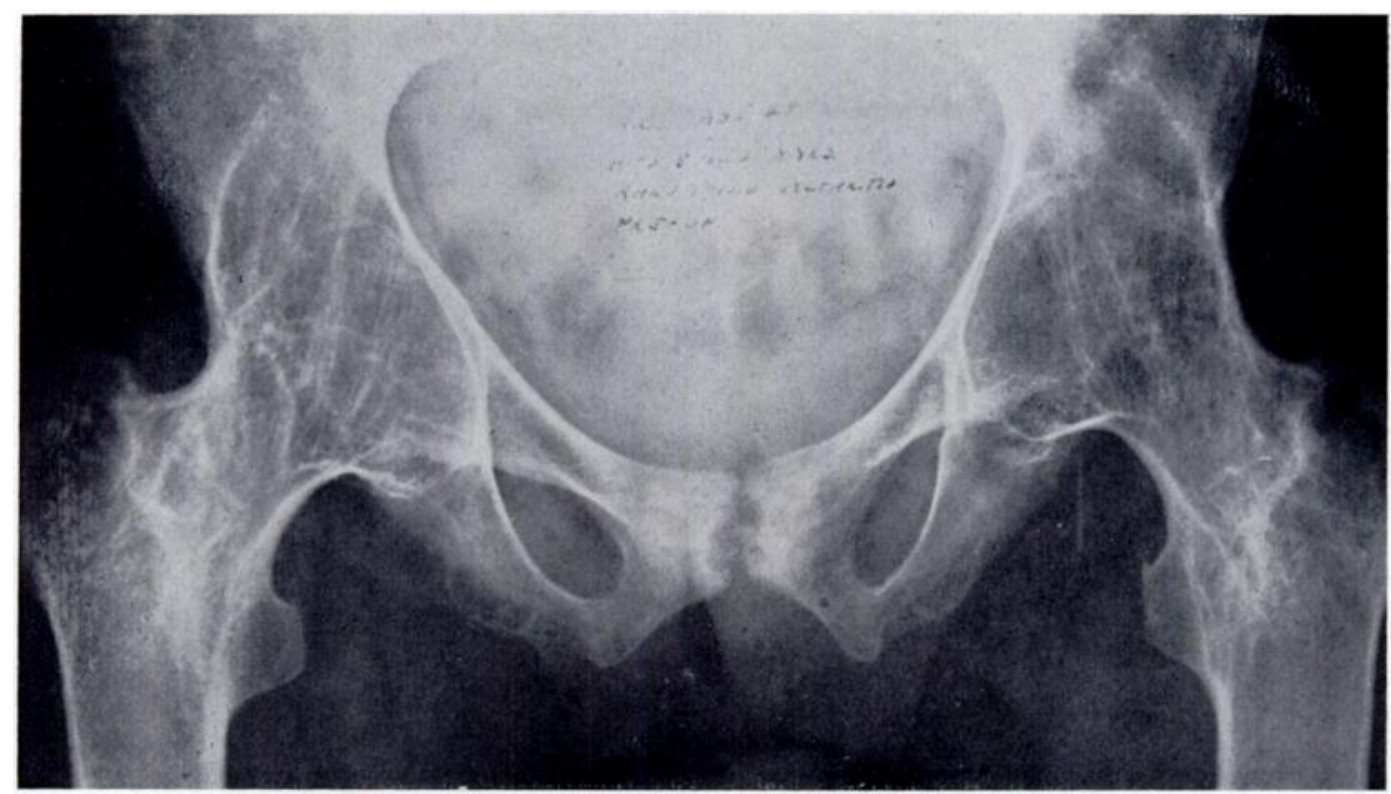

FIG. 15

B. C. Typical case of rheumatoid arthritis of ten years' duration in a thirty-year old patient. Rigid, flexed spine; 80 degrees flexion deformity of hips : 25 degrees flexion deformity of knees without evidence of active disease. Minimal involvement of shoulders and hands. Inable to walk except by supporting himself with hands on thighs and using a knee-ankle gait. Bilateral hip arthroplasty performed early in 1940 enabling patient to get around with crutches. Osteotomy of third and fourth lumbar vertebrae in late 1941, allowing patient to stand erect. Not a favourable case for operation because of the advanced bone atrophy accompanied by loss of elasticity and atrophy of soft tissue structures.

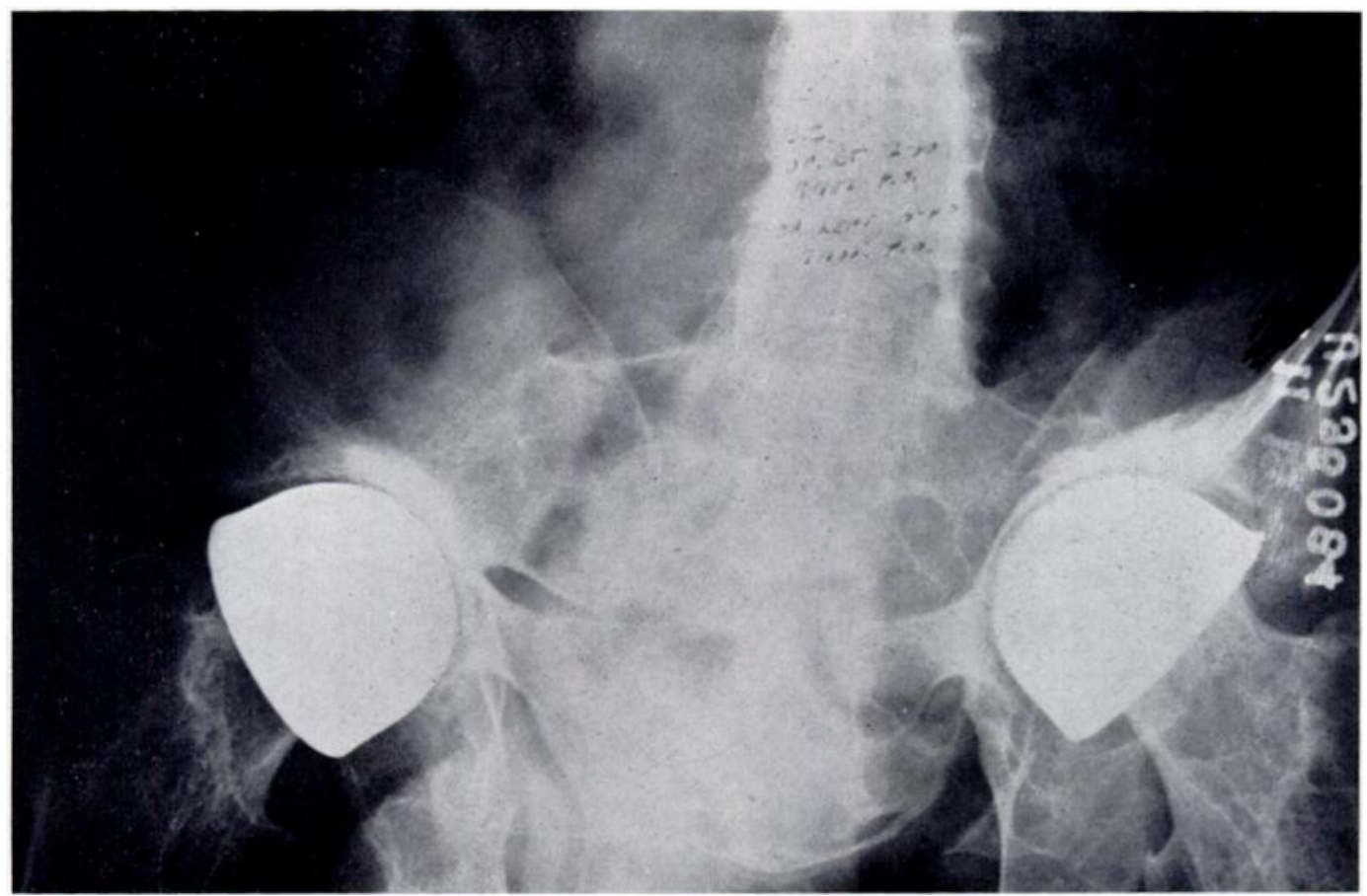

Fig. 16

B. C. Post-operative film of same patient as in Fig. 15; a poor film, but the best available. It is now seven years since the bilateral arthroplasty; there is as yet no indication for revision of the primary procedure. Patient able to put on his shoes and stockings; worked in a factory throughout the war. The large moulds are probably responsible for the relatively mild intrapelvic protrusion of the acetabula.

VOL. $30 \mathrm{~B}$, No. 1, FEBRUARY 1948 


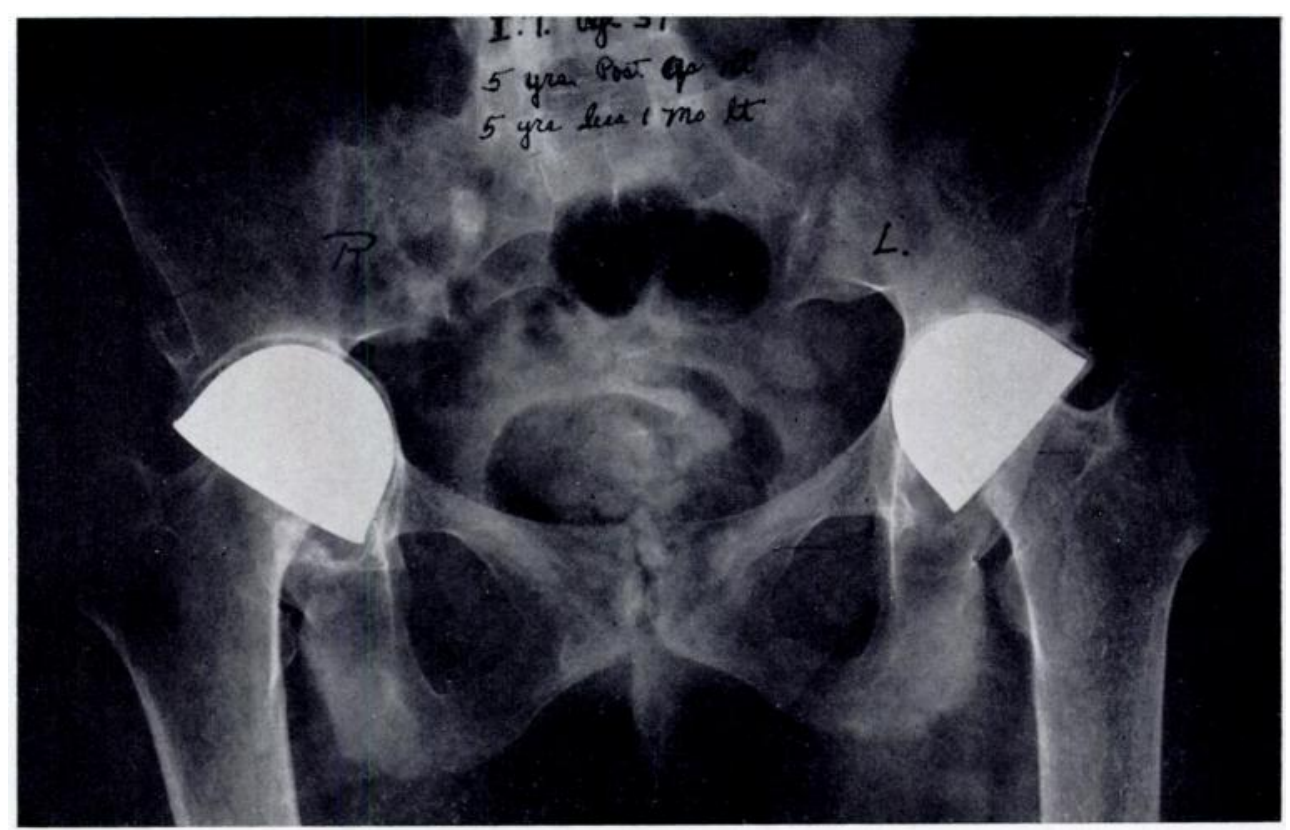

FIG. 17

I. T. This patient was first operated upon for bilateral, bony ankylosis of the hips at the age of thirty-two. She had a rigid spine and involvement of joints of the upper extremities. For five years after bilateral arthroplasties she was able to get around with the aid of crutches and was employed as a librarian. The range of movement became progressively less and it became increasingly difficult for her to sit comfortably. New bone formation and intrapelvic protrusion accounted for the loss of movement. Revision of the primary procedure was decided upon when the range of movement had been reduced to 30 to 40 degrees.

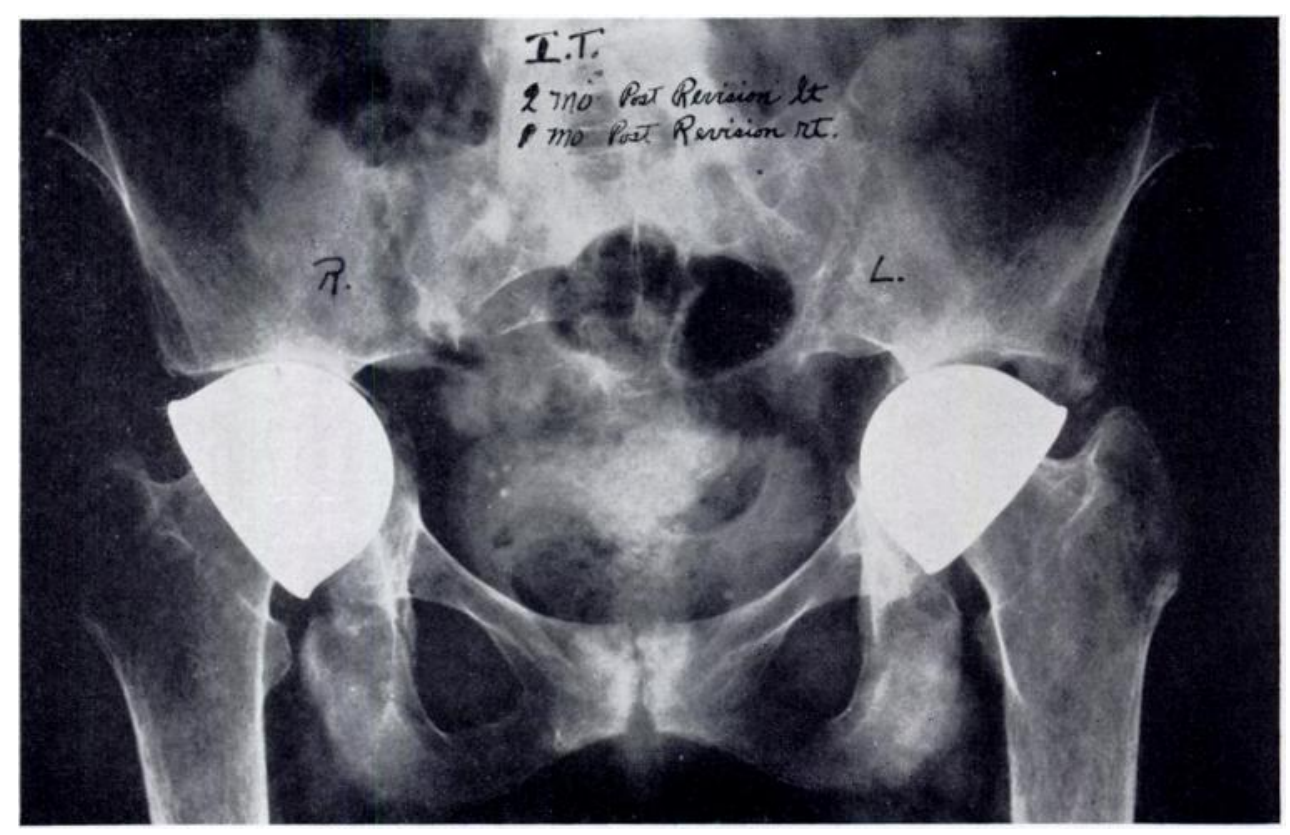

I.IG. 18

I. T. Same case as shown in Fig. 17. Early post-revision X-rays. Radical excision of the superior and posterior acetabulum has been performed; some of the floor of the acetabulum has been sacrificed. It is not yet possible to judge the final result but it is fair to say that the character of the bone at the time of revision had improved markedly from the soft, atrophic bone at the time of the primary arthroplasty. 


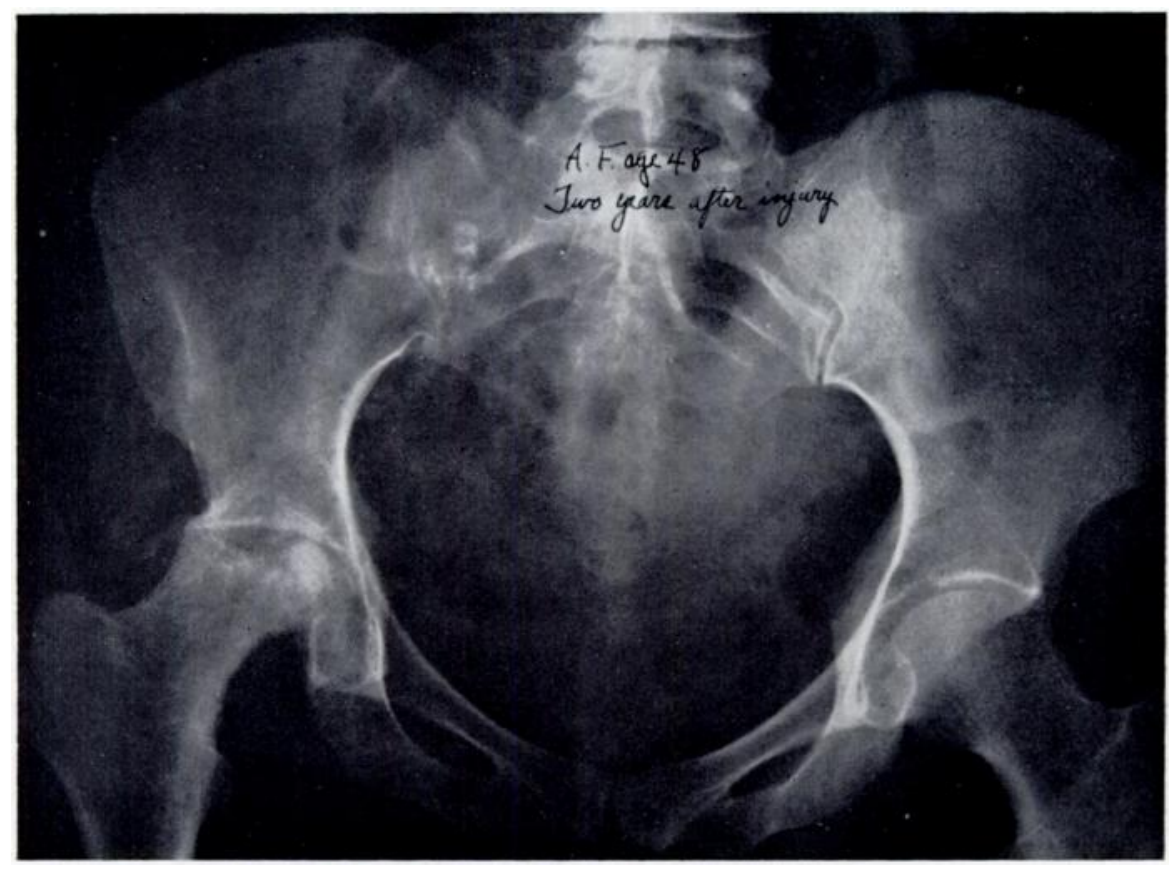

FIG. 19

A. F. Typical case of aseptic necrosis of the femoral head following subcapital fracture of the neck. This patient had no internal fixation of her fracture. A mould arthroplasty was performed two years later because of increasing pain and disability.

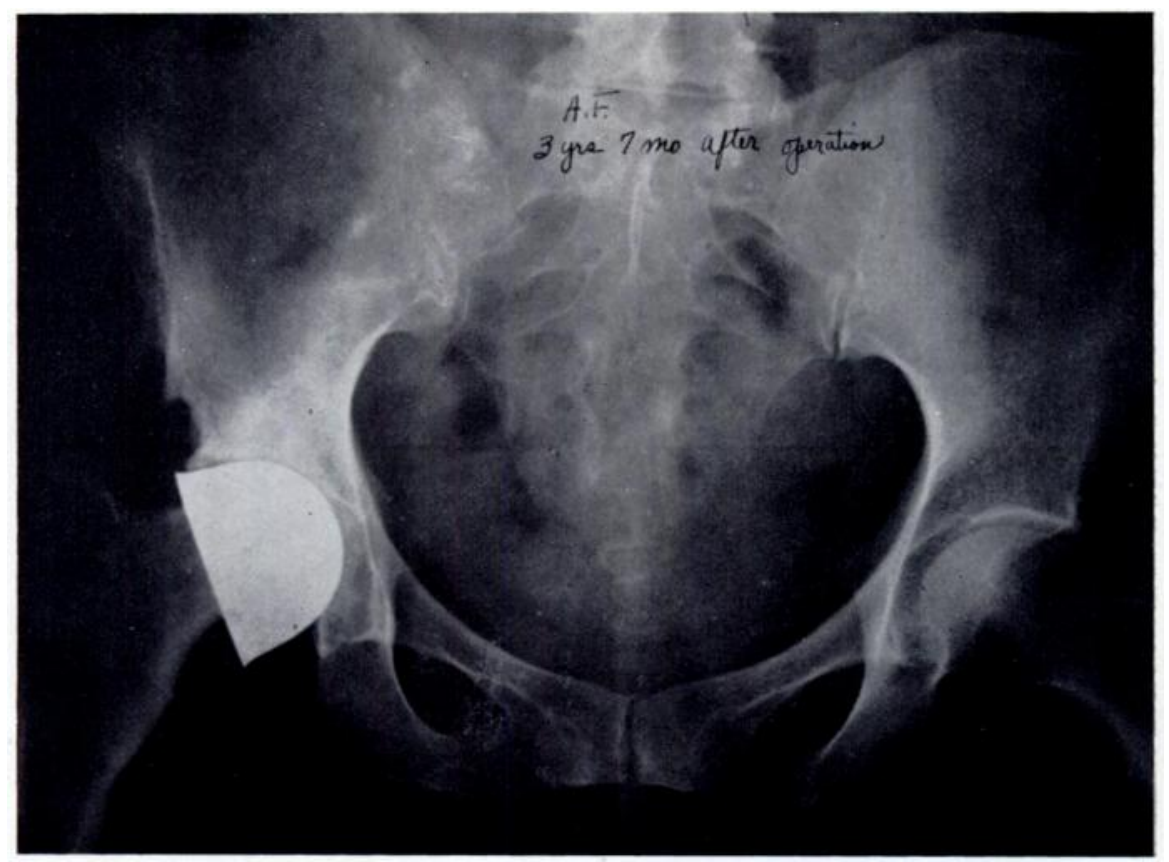

Fig. 20

A. F. Same case as in Fig. 19, three years and seven months after mould arthroplasty. Patient now walks without a limp except when she is tired. She is self-supporting as a music teacher, and is independent of help for any purpose whatsoever. 


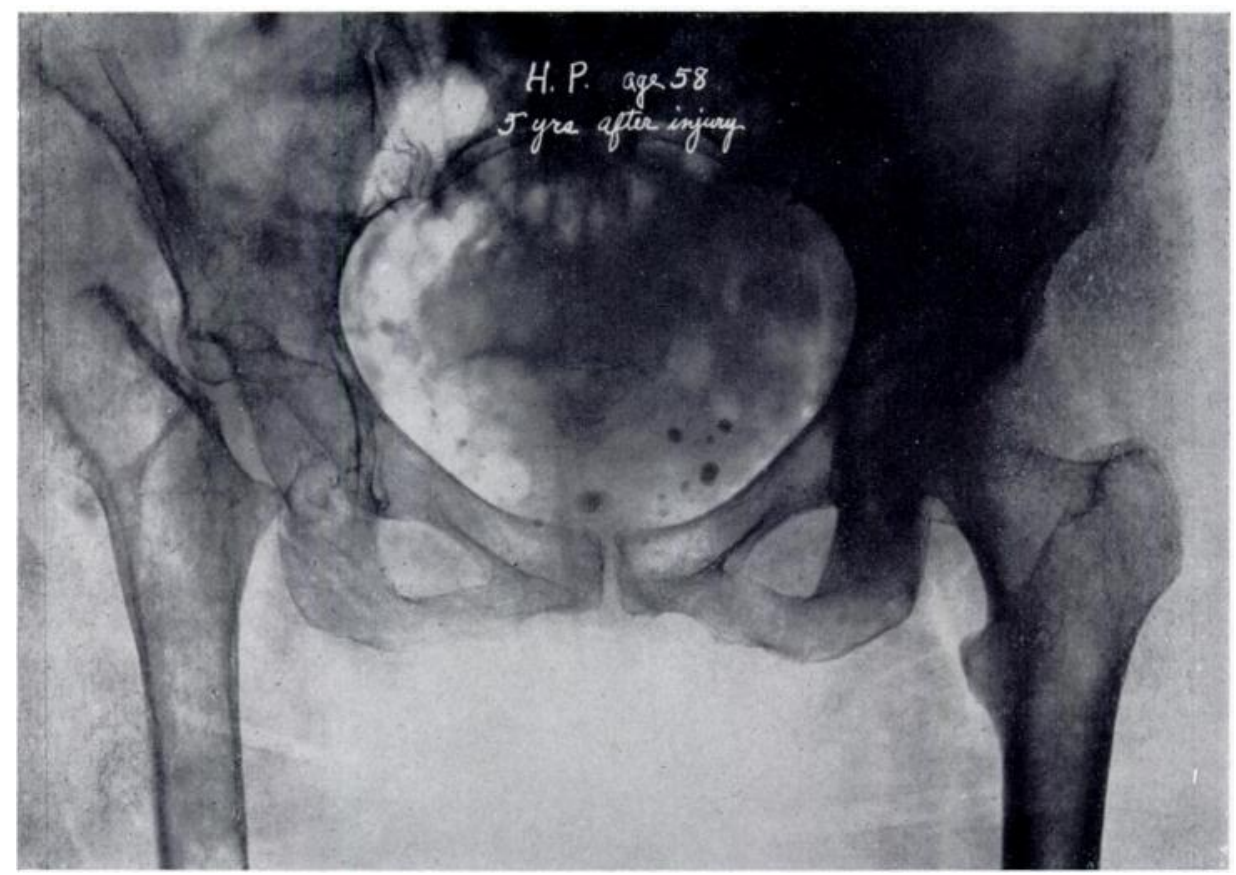

FIG. 21

H. P. A typical case resulting from too much internal fixation. Fractured hip treated by the internal fixation of wood screws. Both the head and neck of the femur have been absorbed to such an extent that they no longer cast a shadow by X-ray.

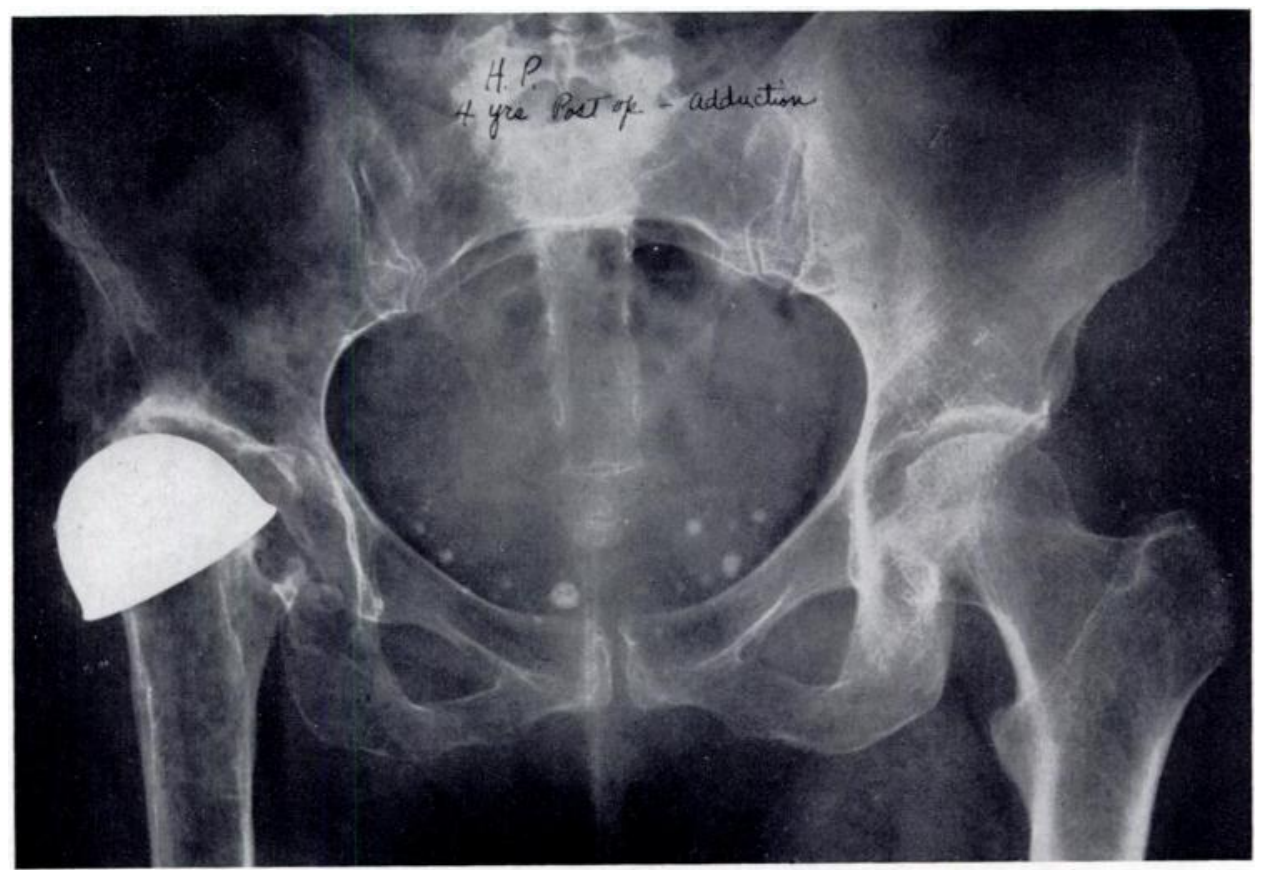

FIG. 22

H. P. Same case as in Fig 21. Four years have elapsed after a modified Colonna operation. A mould has been placed over the greater trochanter. The ilium has been osteotomised vertically in order to extend the acetabular roof laterally. The lesser trochanter has been partly excised to prevent impingement on the posterior lip of the cotyloid notch. Patient is free from pain and has a range of movement more than sufficient for all purposes. Her hip is relatively weak; she uses a walking stick for long distances but never in the house. 


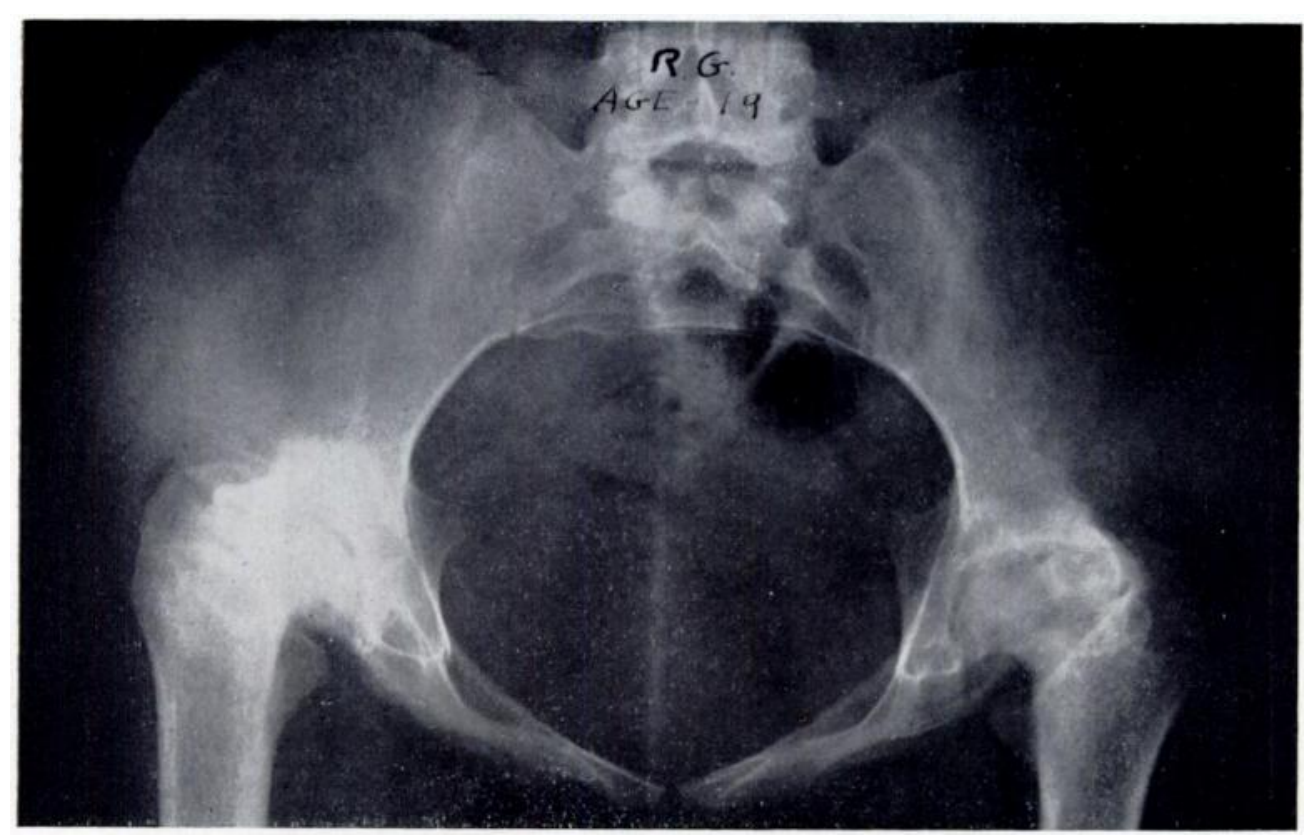

Fig. 23

R. G. Typical case of bilateral septic arthritis of the hip joints in early childhood. When first seen the patient was nineteen years old and just graduating from High School. She was suffering severe pain and found it extremely difficult to assume the sitting position for any length of time. This film shows extensive destruction of the hip joints, with a varus relationship of the remnants of the head and neck to the shaft of the femur

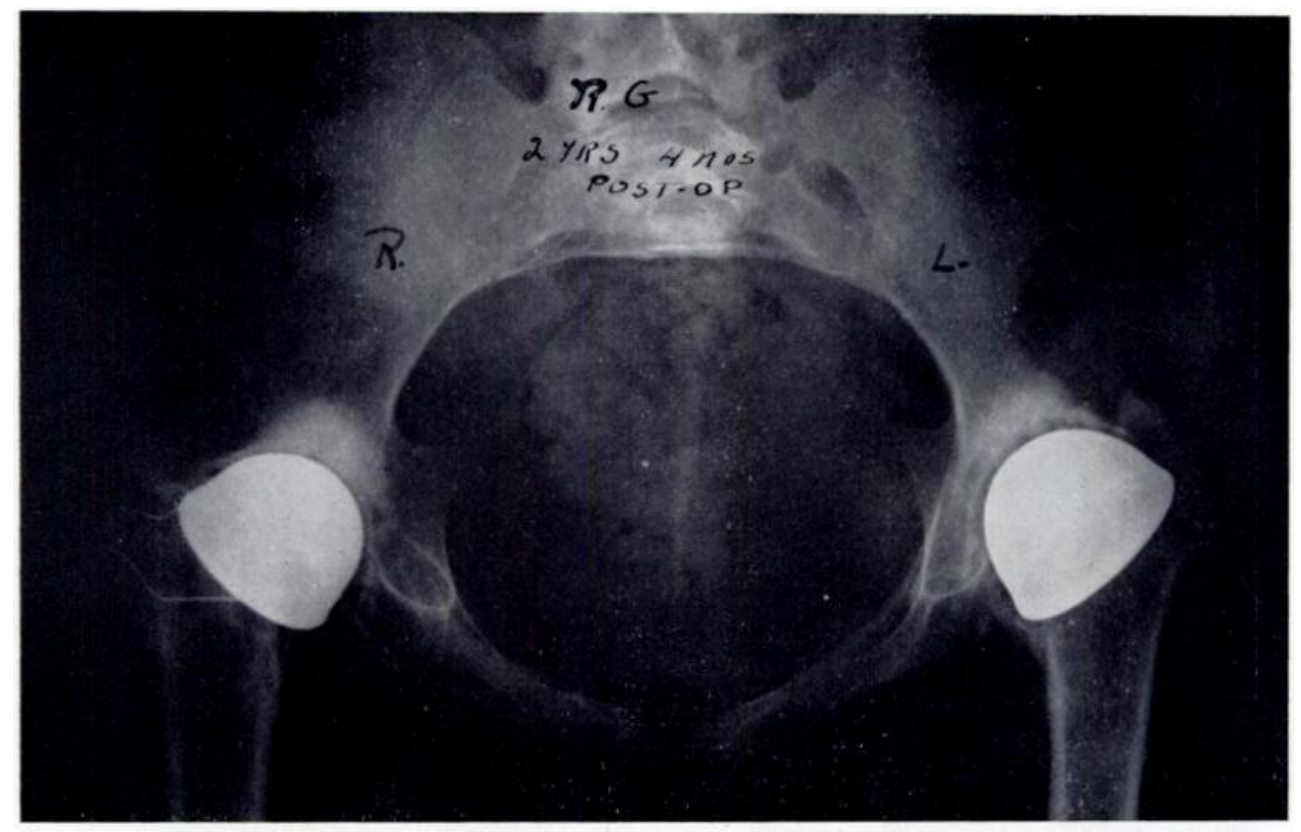

Fig. 24

R. G. Same case as shown in Fig. 23, a little over two years after bilateral mould arthroplasty. On the right, the greater trochanter has been transplanted downwards in order to eliminate mechanical interference. This was done as a secondary procedure some months after the primary arthroplasty. On the left, symptoms have not yet developed sufficiently to justify a similar procedure. There is evidence of benign repair in response to the mould. This patient is able to do the work of a secretary and is relatively free from pain. The range of movement in her hips is not such that she is independent of the help of others. Further operative treatment will unquestionably be necessary.

VOL. $30 \mathrm{~B}$, No. 1 , FEBRUARY 1948 


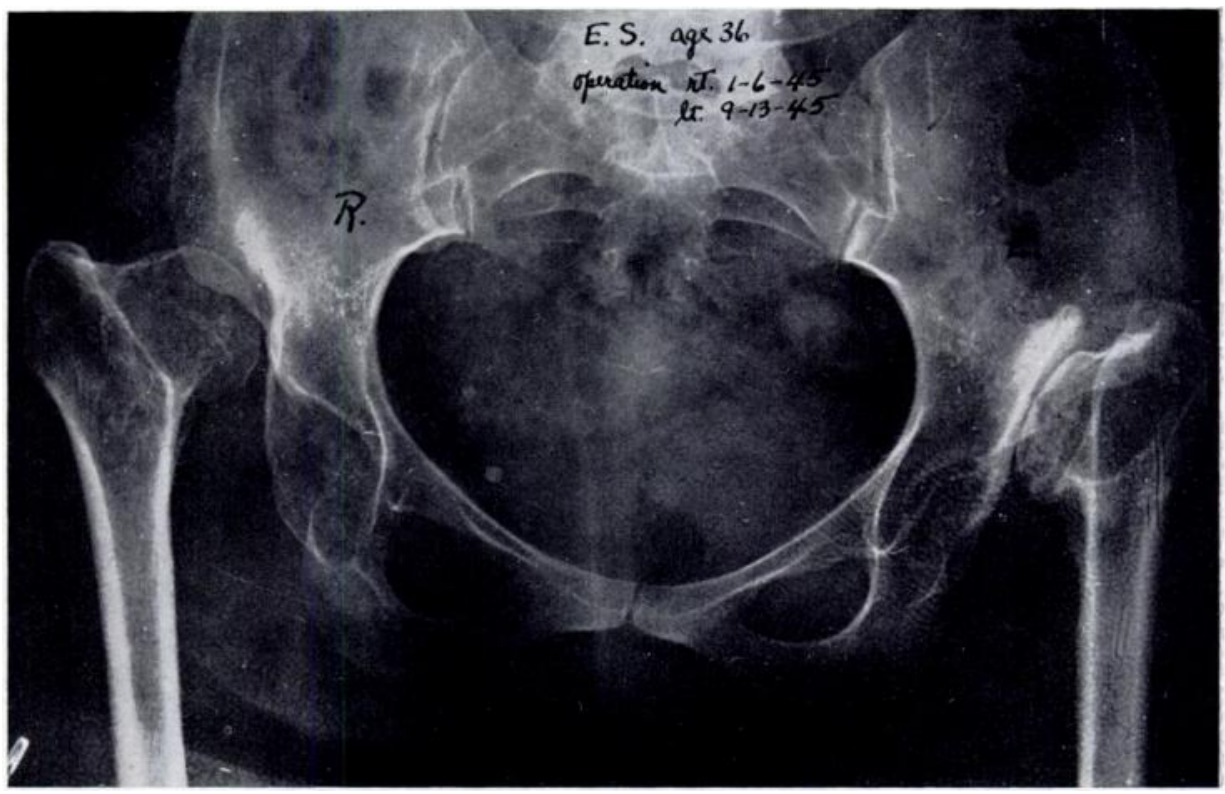

FIG. 25

E. S. Bilateral dislocation of the hip joints in a woman of thirty-six. Trencielenburg markedly positive on both sides, left more than right. Considerable pain arising from both hips and low back. Left hip presented a difficult problem because of the absence of the femoral neck.

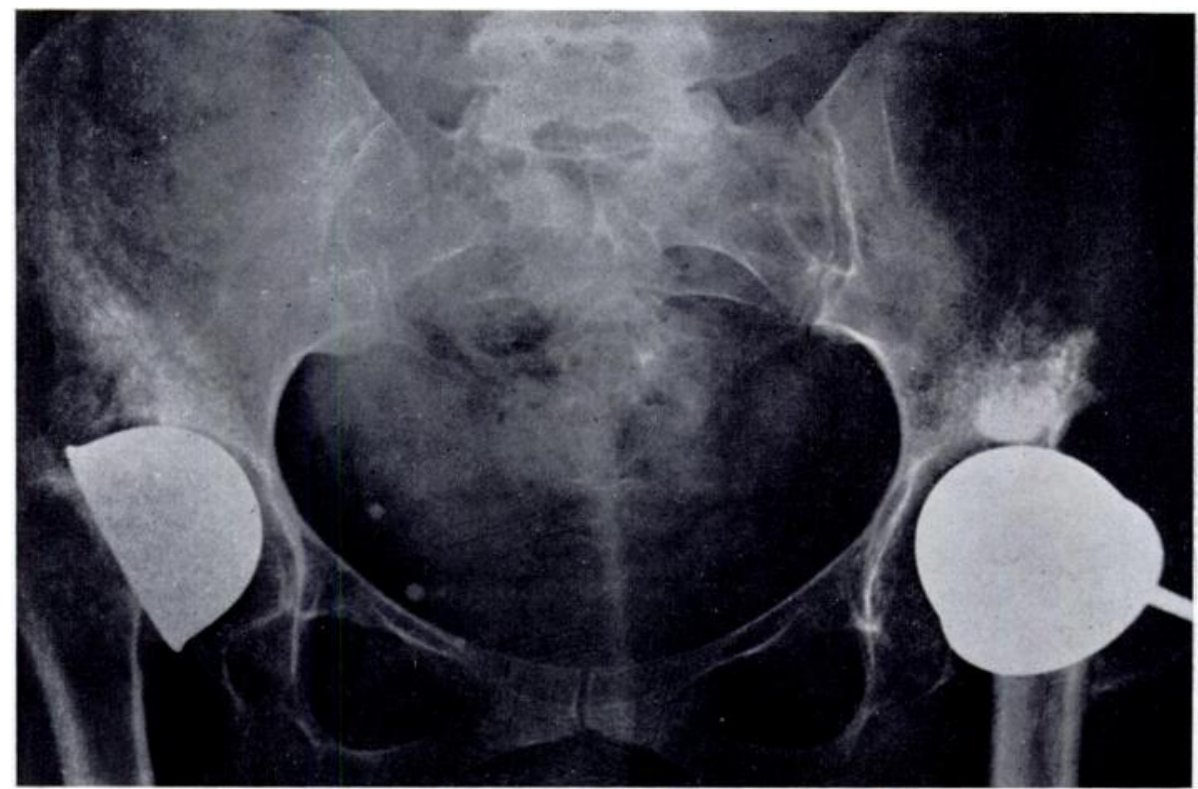

FIG. 26

E. S. Same patient as in Fig. 25; post-operative film. The right hip was operated upon in January 1945. It was possible to create a new deep acetabulum at a level corresponding closely to the original acetabulum, and to extend the acetabular roof laterally by vertical osteotomy of the ilium. By transplanting the femoral head from a lateral to a mesial position, increased stability and improved muscular leverage was accomplished. At this time, two years after operation, the Trendelenburg sign is negative and the range of movement is sufficient for all purposes.

The left hip was operated upon eight months later, September 1945. Between operations patient got around on crutches but had to wear a two-inch high sole on the left. The operation on the left was essentially the same as on the right, but it was necessary to transplant the trochanter downwards because of the absence of the femoral neck.

At this time, one and a half years after operation, the left hip has the same range of movement as the right, but it is definitely a weaker hip. The Trendelenburg sign has been diminished but not eliminated. Because of this weakness on the left the patient still uses a walking stick on the right. 


\section{REVIEW OF RESULTS}

In 1937 my dentist, Dr John Cooke, suggested vitallium as the ideal material from which to make the moulds. After several unsuccessful attempts a satisfactory mould was obtained. In 1938 the first vitallium mould arthroplasty was performed. Since then over 500 hips have been operated upon by this method at the Massachusetts General Hospital; eighty of these were bilateral. The fact that we have been willing to perform this operation on such an extensive scale is evidence that the results have been satisfactory.

Malum coxae senilis-Eighty-four arthroplasties, six of them bilateral, making a total of ninety, have been performed. The results have been more satisfactory than those of arthrodesis. The range of movement obtained has usually been sufficient to enable the patient to put on shoes and stockings. Most of them have a limp but it is a pain-free limp which allows them to lead an active life (Figs. 13-14).

Rheumatoid arthritis-Seventy-eight arthroplasties, forty-nine of them bilateral, making a total of 127, have been performed. It is fair to say that the results are at least encouraging. The range of movement is not as great as in malum coxae senilis and seldom sufficient to enable the patient to put on shoes and stockings. As a rule the patient's general activities are increased because of relief of pain, and many of them return to active, productive life. The frequent multiple joint involvement-spine, knees, and joints of the upper extremities-easily accounts for the less satisfactory results (Figs. 15-18).

Complications of fractured hips - A total of fifty cases have been operated for non-union, aseptic necrosis, and dead heads. The results are very satisfactory and compare favourably with those obtained in malum coxae senilis (Figs. 19-22).

Old septic hips-Twenty-four cases, eight of which were bilateral, making a total of thirty-two: the discouraging aspect in this group of cases is the post-operative flare of original sepsis. This occurred in eight cases. When this complication does not occur, the results are very satisfactory and the range of movement is better than that obtained in rheumatoid arthritis. This is probably due to the fact that patients in this group are able to be active, and consequently do not have the same degree of bone muscle atrophy, nor do they have limitation of movement of the knee joints (Figs. 23-24).

Congenital dislocations-Forty cases, ten of them bilateral, making a total of fifty: the youngest patient was aged thirteen years, the oldest sixty years. The results are most satisfactory. The main reason for this success is probably the mesial transplantation of the femoral head into a new and deep acetabulum. This results in stability and improved muscular leverage so that the Trendelenburg sign is markedly diminished (Figs. 25-26).

Other conditions-The operative procedure of mould arthroplasty has been applied to practically all conditions to which the hip joint is subject.

\section{SECONDARY REVISIONS OF THE FIRST ARTHROPLASTY}

Fifty-three patients have been subjected to revisions of the first arthroplasty. These revisions have been necessary to a great extent because of errors in technique and judgment during the early development stages of the procedure.

Revision for calcification of rectus tendon-Leaving the proximal stump of the rectus tendon attached to the inferior iliac spine, so that the distal tendon could be resutured to it, was a mistake. In several cases the proximal stump became calcified, and interfered with the range of flexion movement. This difficulty has been overcome by dividing the rectus tendon close to the inferior spine, then suturing it at the end of the operation to the reflected head of the rectus, or to the tendon of the gluteus minimus.

Revision for enlargement of acetabulum-The need for a relatively large acetabulum was not fully appreciated at first. By enlarging the acetabulum mesially and inferiorly, more stable relationship for weight-transmission is obtained and the mould is less apt to catch on the posterior lip of the cotyloid notch.

VOL. $30 \mathrm{~B}$, NO. 1, FEBRUARY 1948 
Revision in rheumatoid arthritis-Many patients with rheumatoid arthritis have been operated upon a second time because of a decreasing range of movement. In most of these there was considerable bone and muscle atrophy at the time of the primary arthroplasty. Exercises aiming to overcome lack of elasticity of contracted structures and to restore muscle power forced the mould against the soft atrophic bone, bringing about gradual

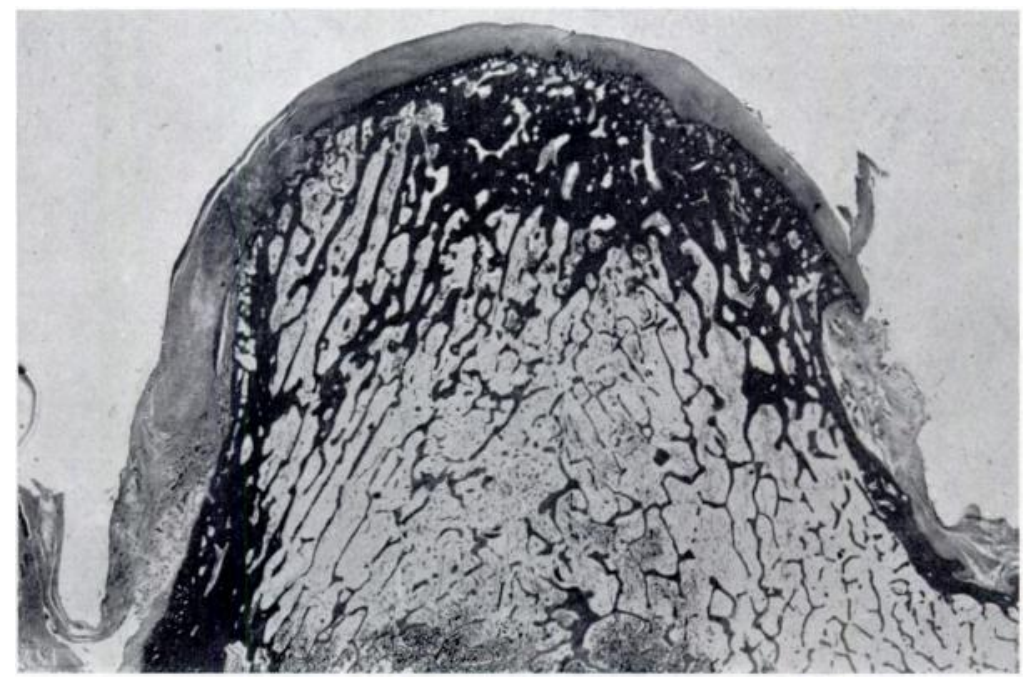

Fig. 27

Section of femoral head removed at autopsy five years after glass-mould arthroplasty, three years after replacement by a vitallium mould.

deepening of the acetabulum. Intrapelvic protrusion of the acetabulum was not an uncommon result. Naturally this diminishes the range of movement but does not eliminate it. Even the limited function obtained in these patients brings about improvement in the character of the bone, so that secondary revision can be undertaken two or more years after the primary procedure under much more favourable conditions.

Revision when first operation complicated by sepsis-Operative sepsis has been responsible for a small number of revisions.

\section{COMPLICATIONS}

Post-operative sepsis-Twenty cases; eight of these occurred in patients with old septic hips, and infection developed several weeks or months after operation. If we can interpret these cases as flares of the original infection, which seems legitimate, operative infection in 500 arthroplasty procedures is reduced to twelve. It is fair to say that, with the use of chemotherapy in one form or another, post-operative infections should be still further reduced. During the last year we have had no operative sepsis in more than fifty hip arthroplasties.

Pulmonary embolism-Pulmonary embolism has occurred, but never with fatal outcome. Vein ligation has been resorted to in a limited number of cases. In a series of sixty arthroplasties undertaken in complications of fractures of the neck of the femur, vein ligation was undertaken in one case.

Mortality-In this series of approximately 500 arthroplasties there has been no operative mortality. 


\section{CONGLUSIONS}

This is the first time that the principle of the mould-the principle of guiding the repair of nature for the purpose of recreating a destroyed or damaged structure, has been applied to surgery. The evolution of the method to its present encouraging stage is the result of the co-operative, professional family spirit of the Massachusetts General Hospital. We all share in it. We share it with the general surgeon because of his contributions to surgical technique. We share it with the "medical man" because of his pre-operative and post-operative care of the patient; because of his guidance as to when, and when not, to operate; and because of the many friendly arguments which are productive of so much good. We share it with the anaesthetist because of his clinical judgment of the patient, his selection of anaesthetic agent, and his continuous, conscientious administration of the anaesthetic throughout the operation.

I am going to change from "we " to "I." I owe so much to my assistants, from the first to the last: Bill Rogers, Eddie Cave, George Van Gorder, Paul Norton, Milton Thompson, Otto Aufranc, and Carroll Larson. I want to thank them all for helping to carry the load, for remembering the things that I forgot, and for making helpful suggestions which often led to improvement in surgical technique or to the construction of a useful instrument. I want to pay tribute to the staff of the Orthopaedic Service of the Massachusetts General Hospital and to thank its members for kindly scepticism, constructive criticism, and neverfailing loyal support.

The subject of this lecture, "Evolution of Mould Arthroplasty of the Hip Joint," is appropriate for a Moynihan lecture. It is not the work of one man alone. It is the work of one man, supported by a co-operative, helpful, and friendly hospital staff. This is what Lord Moynihan strove so hard to bring about at a time when surgeons viewed one another as rivals. To quote Dr William Mayo: "It is to Lord Moynihan's everlasting credit that, largely as a result of his unceasing efforts, surgeons came to consider themselves as fellowworkers in a cause." 